\title{
Turning to Service, Preliminary Study of a Wood Conventional Semi Industrial Dryer and Cost Price of the Wood Drying in the African Tropical Context
}

\author{
Merlin Simo Tagne ${ }^{\mathrm{a}, \mathrm{b}, *}$, Romain Rémond $^{\mathrm{c}}$, Yann Rogaume $^{\mathrm{c}}$, André Zoulalian $^{\mathrm{c}}$, Eric Mougel $^{\mathrm{c}}$ \\ ${ }^{a}$ Douala Higher Institute of Technology, PO Box 1623, Douala-Cameroon \\ ${ }^{b}$ Association for Research and Promotion of Sustainable Energy in Central Africa (ARPEDAC) \\ ${ }^{c}$ University of Lorraine, LERMaB, PO Box 1041-88051, Epinal- France
}

\begin{abstract}
As all apparatus used permanently or not, dryers of wood require a regular maintenance in other that the entry orders are effectively operated in the dryer and these components: interior air, interior wall and wood during the drying. This maintenance also permits to obtain the real values of the measured orders to following very well the drying operation. In this paper, we present the equipment and the calibration of wood semi industrial dryer of the National Higher College of Wood Technologies and Industries (ENSTIB) of the University of Lorraine situated at Epinal-France. These actions are much importance to use this dryer for the serious scientific studies. Then, the results that we have obtained in this dryer are analyzed and validated. Ayous wood (Triplochiton Scleroxylon) is used, because desorption isotherms are well-know and desorption energy is deducted very easily. We have also estimated the appropriated wood waste to bring the energy needed by combustion. An estimation of the cost price of the drying of wood is doing in order to motivate the workers of the domain.
\end{abstract}

Keywords: Wood dryer, calibration, drying kinetic, enthalpy, cost price, ayous, tropical woods.

\section{Introduction}

After petroleum, wood is the second product most exported from Cameroon. According to the studies of Perry and Kolokosso [1], the exportation of wood gives in the State in 2005 almost 228 milliards of Francs CFA ( $1 €=655.9$ FCFA). In 2007 , this amount was estimated more than 500 milliards of F.CFA [2]. In 2009, the number of the workers in the forest domain was estimated at 45000 . But only, almost all these workers don't study these specific formations in the school. When this formation exists, it is reduced at the work as the cutting down, joinery or transport. The interdiction of the Cameroonian's State (like that Gabonese State and others) to export some rough imber obliges to ameliorate the knowledges in the conservation domain and in the treatment of wood. For this reason, the conduct of the dryers and their maintenance are obligatory, because after cutting up, the wood may always to be dried in order to be the most preserved. The calibration of apparatus to measure is an obligated stage. It will permit to obtain a good value given by the apparatus. Thus, these

${ }^{*}$ Corresponding author. Tel.: +237 694852402

E-mail: simotagne2002@yahoo.fr

(C) 2015 International Association for Sharing Knowledge and Sustainability

DOI: $10.5383 /$ ijtee.09.02.005 apparatus operates correctly and the entry data and the exit data are really these which operate in the dryer. In this paper, we present the equipment of wood semi industrial dryer of the National Higher College of Wood Technologies and Industries (ENSTIB) of the University of Lorraine situated at Epinal in France. Then, the calibration of the apparatus is made in order to deduct the drying kinetic of Ayous. This drying kinetic permits to obtain the mass coefficient diffusion of studied wood. Also, we have estimated the cost price of the drying process in the context of Cameroon particularly, and the Africa Central region generally.

\section{Methodology}

\subsection{Presentation of the dryer}

The semi industrial dryer have been utilized by Romain REMOND during the work of his thesis of Doctorate [3].This dryer is presented in figure 1a below. It is utilized by the students during their practical works in order to judge the quality of dried woods. In our study, we were equipped this 
dryer with the masses sensor (figures $1 \mathrm{~b}, 1 \mathrm{c}$ and 1e), device of acquisition in continued masses and temperatures (figure 1c). Entries data and control the thermo physical parameters can to be possible according to two ways: a box of command situated nearly the dryer (figure 2a) and a monitor room incorporated of one personal computer where has a computer program with an interface which facilitated the control of the dryer (figure $2 b$ ). Figure 1d presents the planks of ayous wood utilized. We have used a one-dimensional drying with to use aluminium sheet fixed at the two sides of the planks.

Figure 3 is the detailed scheme of our drying. The volume of the drying enclosure is estimated to $0.4 \mathrm{~m}^{3}$. The resistor $\mathrm{R}$ permits to heat the air. The generator of vapor $G$ (Electro-vap EL5) is necessary to humidify the air. Air is dehydrated by the cold battery $\mathrm{C}$ (condenser). The resistor $\mathrm{R}$ permits to heat the air. The Gap Vp permits to adjust the air rate accelerated by the fan $\mathrm{V}$, the values of the air rate changes between 600 and $2000 \mathrm{~m}^{3} / \mathrm{h}$ and measured by the flowmeter D.
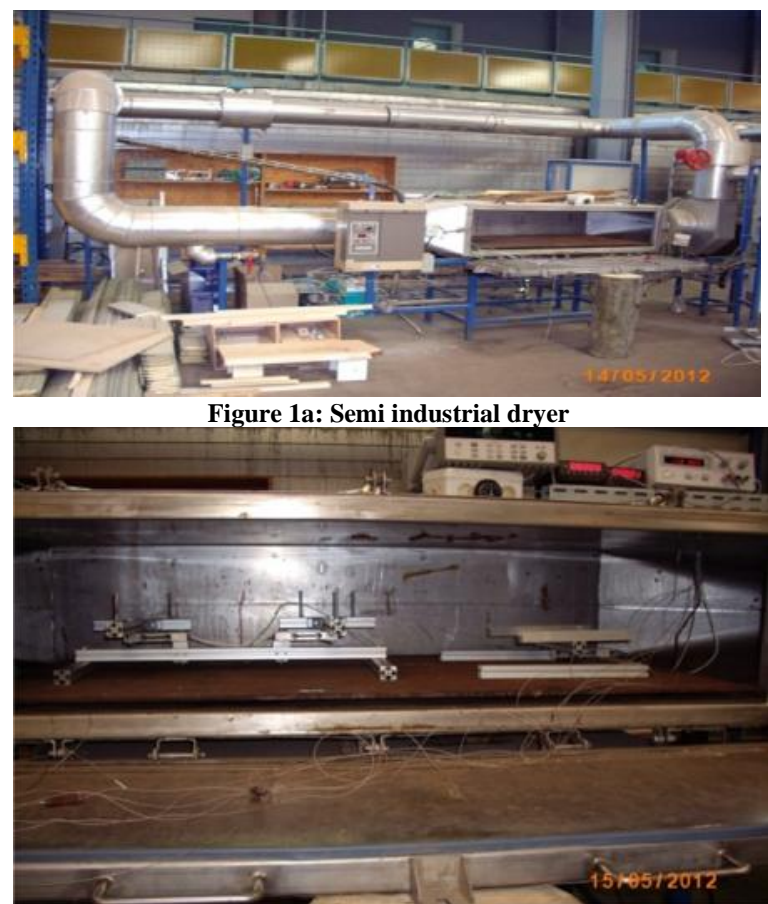

Figure1b: Enclosure of the dryer which contained masses sensor

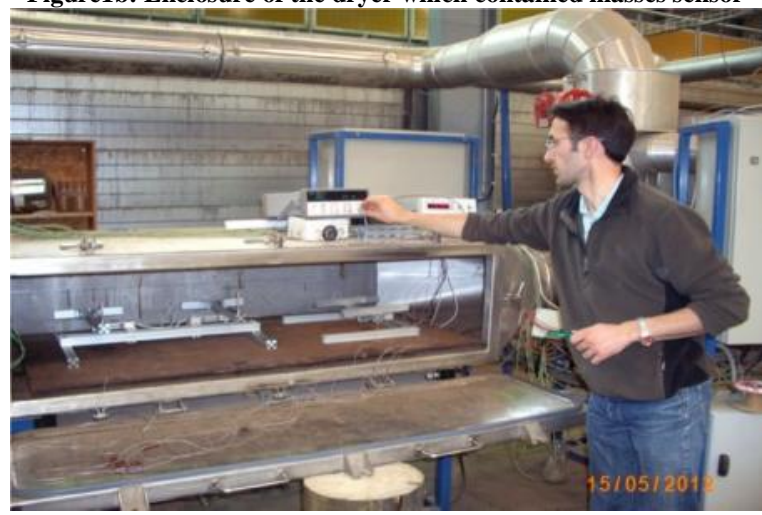

Figure 1c: Arrangement of the apparatus of acquisition by $\mathbf{R}$. REMOND

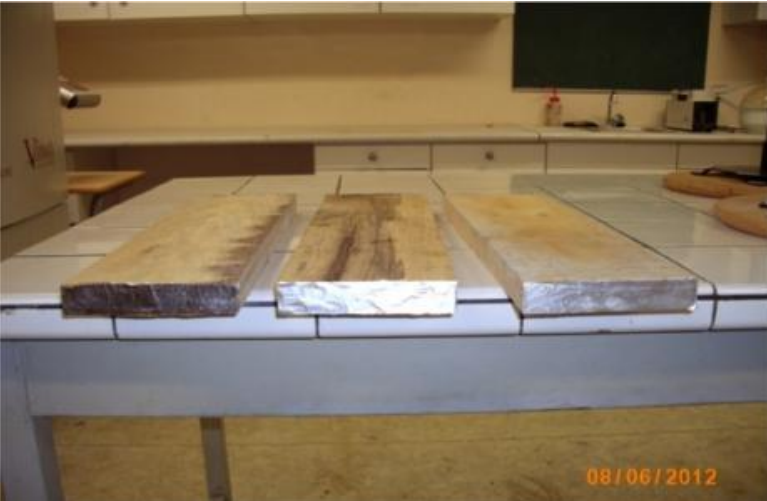

Figure 1d: Planck of wood utilized (ayous)

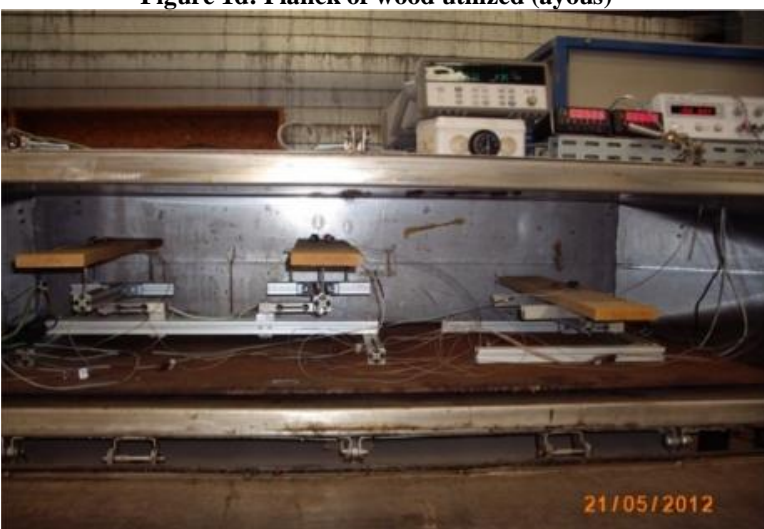

Figure 1e: Disposition of the planks using for the test.

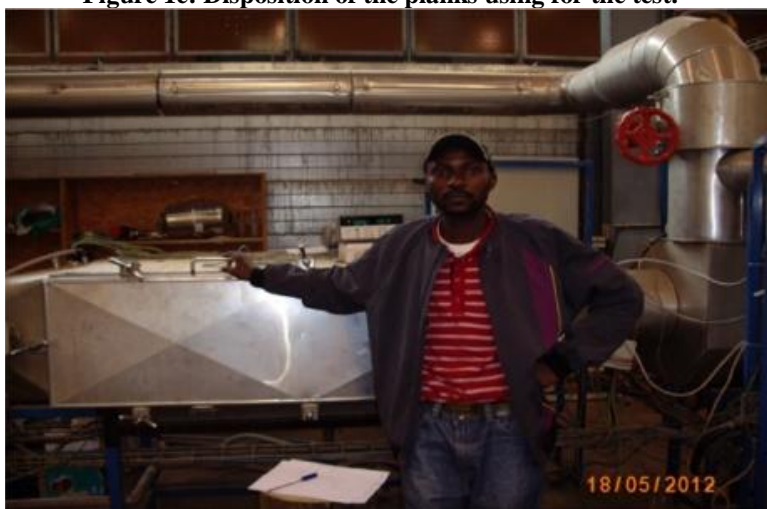

Figure 1f: Closing-down to start the drying by M.SIMO TAGNE Figure 1: Equipment and calibration of the dryer

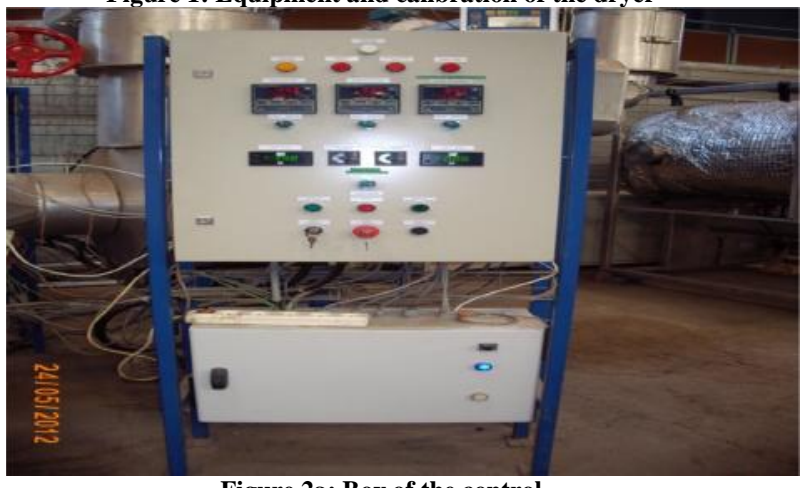

Figure 2a: Box of the control 


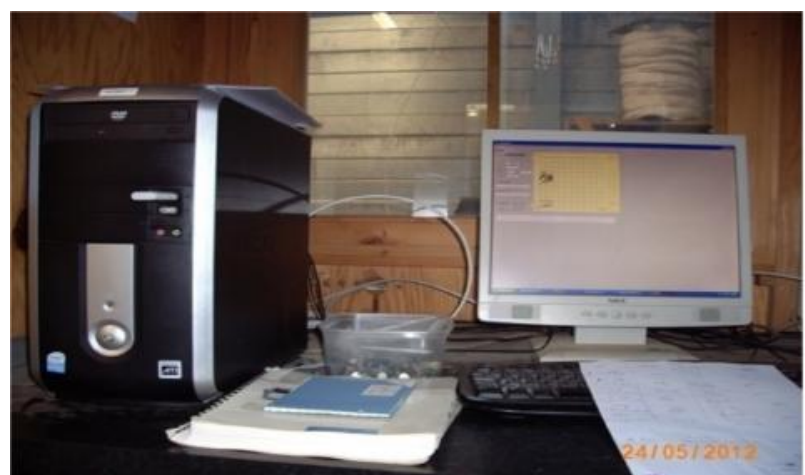

Figure 2b: Monitor room of the control and acquisition Figure 2: Instruments of control of the dryer

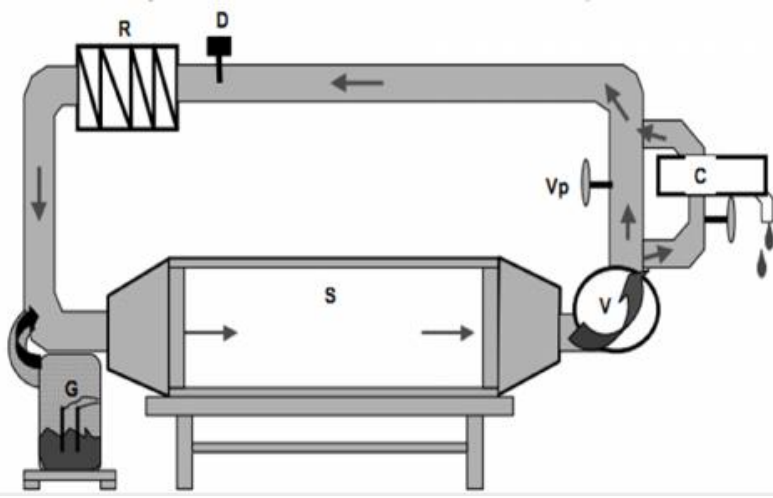

C: Condenser; D: Flowmeter; G: Generator of the vapor; R: Resistor; S: Enclosure; V: Fan; Vp: Gap.

Figure 3: Drying with the heat air utilized [3]

\subsection{Calibration}

In order to be sure that the administrated values are recorded and effectively used in the dryer, we have calibrated ours sensors of mass and temperature. The process is following:

For the mass sensors, we have utilized a combination of the marked masses (figure 4) and we have do a correspondence between the values of the masses obtained and the values of the tensions respectively recorder in the file presents in the computer of control.

For the temperature sensors, we have utilized water in the knowing different temperatures. Three temperatures have been utilized: the ambient temperature, a forced temperature nearly to $0^{\circ} \mathrm{C}$ by the fragment of glass and a forced temperature nearly to $100^{\circ} \mathrm{C}$ obtained with heated water until ebullition.

The temperature sensors are putted in the water at different temperatures and the values of the respective tensions are noted in order to do a correspondence between the values of fixed temperature (real values) and the values of the tensions given by the sensors in platinum Pt100. This exercise permits us to obtain the equation of the calibration. The figure 5a presents a temperature sensor where we have putted the cotton in the extremity with the demineralized water in order that this sensor gives a humid temperature. The figure $5 \mathrm{~b}$ presents some mass sensors utilized to evaluate the surface and heart temperatures of ours woods. To test the functioning of the added components in the dryer, we have used the sample of oak (figure 1e) and the duration of this test is 5 days. We have obtained that the variation of temperature has an important effect on the acquisitions. For this reason, we have used a drying with a constant temperature.

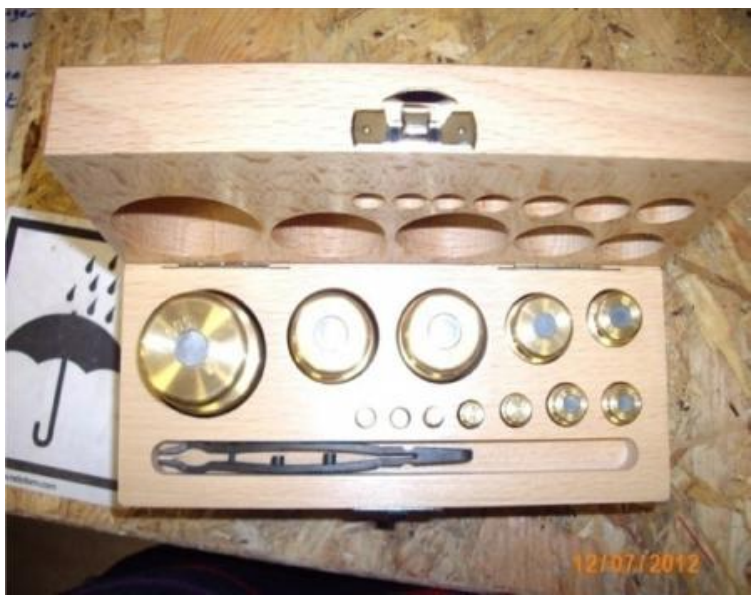

Figure 4: Box of masses utilized to calibrate the mass sensors

Figure 6 presents the distribution of the lines at the same tension and the lines of current created by the electrodes using to measure the humidity of the plank. In our study, the electrodes are putted until the heart of the plank in order to determine the humidity at this level and near of the surface in order to estimate the humidity at the surface of the planks. The megohmeter permits us to measure the electric resistance $\mathrm{R}$ between the potentials $\mathrm{V}_{1}$ and $\mathrm{V}_{2}$. The work of Kouchadé [4] gives the electric resistance when the sensors are placed in the distance $d$.
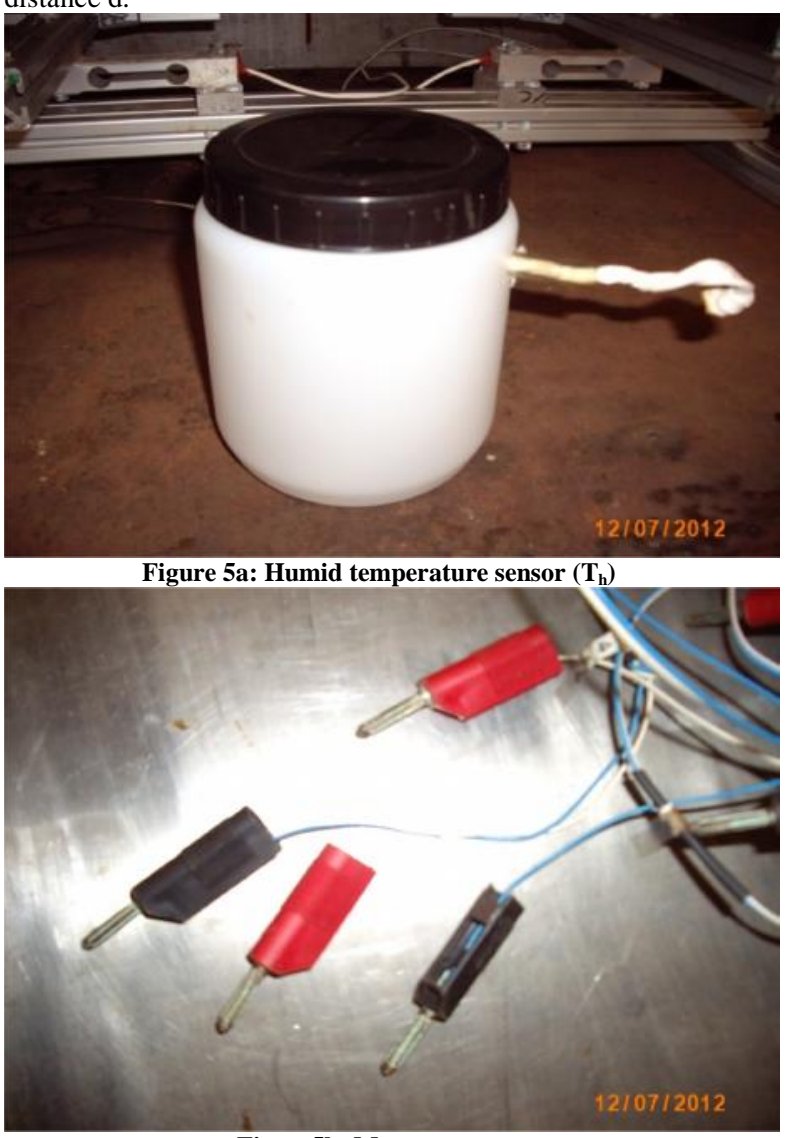

Figure5b: Masses sensors

Figure 5: Sensors for acquisition the humidity and temperatures of the samples 


$$
\varphi=\frac{e R \pi}{\ln \left(\frac{r_{e}+d}{r_{e}}\right)}
$$

Know that:

$R=\frac{U}{l}$

$\varphi$ is the electric resistivity and $r_{e}$ the ray of the borer.

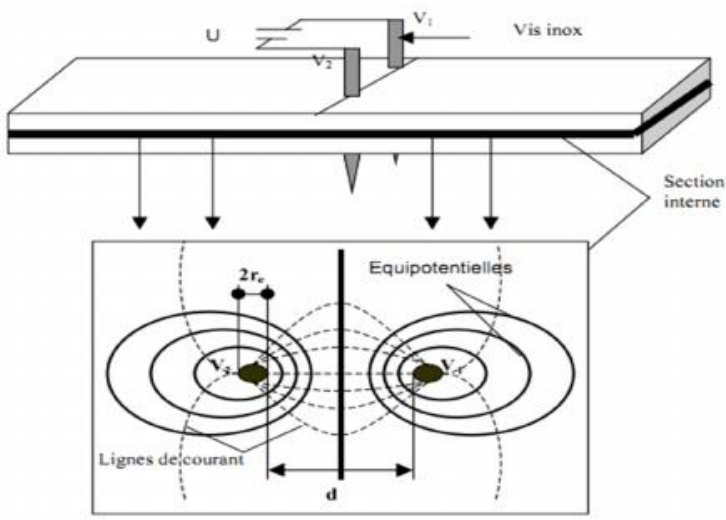

Figure 6: Distributions of the line of the same tension and the line of the current created by the electrodes [4]

In 1927, Stamm [4] shows that the resistivity of wood varied with the water content $\mathrm{X}$ when the temperature is constant according to the following relation:

$\ln (\varphi)=a 1+b 1 \ln (X)$

$\mathrm{a} 1$ and $\mathrm{b} 1$ are the constants defined at the given temperatures. Thus, when the electric resistivity in know, the water content of the wood can to be deduced. An exploitation of the value of the resistivity can to be doing to deduce the temperature $\mathrm{T}$ of the wood. Clark et al. (1933) propose the following relation at the constant water content [4]:

$\ln (\varphi)=c 1+\frac{d 1}{T}$

$\mathrm{c} 1$ et $\mathrm{d} 1$ are the constant defined at a given water content.

According to the precedent relation, it is important to take a suitable distance $d$ in order to respect the distribution of the line at the same tension and the lines of current. Humid meters are almost made in Europe and made to functioning at the temperatures near to $20^{\circ} \mathrm{C}$. In order to use apparatus in the tropical environment, then the calibration is an important process.

\section{Results and Discussion}

\subsection{Determination of the dryer's characteristics}

Tables 1 and 2 present equations of calibration respectively of the temperatures and masses obtained. We noted that curves of calibration permit only to correlate the experimental points and cannot have a theoretical significance on the physical mechanisms presented.

Figure $7 \mathrm{a}$ below shows evolutions of the principal volumetric rates of the dryer. Recall that the principal rate is the volume air treated by the unity of the time given in the enclosure of the dryer in order to maintain or almost the conditions of the fixed temperature and humidity. We noticed a variation of the values during the second test. This variation shows the instability of the exterior atmospheric conditions, the dryer is obligated to reduce or to increase the volume of the treated air in order to respect the orders that we have fixed in entry. This test is doing during the month of May 2012; climatic conditions of the town of Epinal were in general less steady. The first test is obtained in the period that the exterior climatic conditions of the town were almost steady. Figure $7 \mathrm{~b}$ shows the secondary rates of the two tests, temporal volume of the air using to cool the air in circulation in the dryer. We have obtained the important values in the second test, for the reasons given above. Table 3 gives the type of the rate, dimensions of the planks, initial and final masses and water content.

Table 1: Equations of Calibration of the Thermocouples

\begin{tabular}{|c|c|}
\hline Thermocouples & Equations \\
\hline $\mathrm{Th}_{105}$ & $\mathrm{~T}_{105}=1.0104 \mathrm{U}_{105}+1.9161$ \\
\hline $\mathrm{Th}_{106}$ & $\mathrm{~T}_{106}=1.0143934 \mathrm{U}_{106}+1.8613$ \\
\hline $\mathrm{Th}_{107}$ & $\mathrm{~T}_{107}=1.016363 \mathrm{U}_{107}+1.9768$ \\
\hline $\mathrm{Th}_{108}$ & $\mathrm{~T}_{108}=1.00265 \mathrm{U}_{108}+2.03624$ \\
\hline $\mathrm{Th}_{109}$ & $\mathrm{~T}_{109}=0.98193 \mathrm{U}_{109}+1.9488$ \\
\hline $\mathrm{Th}_{110}$ & $\mathrm{~T}_{110}=0.9819 \mathrm{U}_{110}+2.0185$ \\
\hline
\end{tabular}

$\mathrm{U}_{\mathrm{i}}$ is the tension in $\mathrm{mV}$ given by the Personal Computer by the thermocouple $i$ and $T_{i}$ is the value of the correspondence temperature in ${ }^{\circ} \mathrm{C}$.

Table 2: Equations of the Masses Sensors

\begin{tabular}{|c|c|c|}
\hline \multirow{2}{*}{$\begin{array}{c}\text { Mass } \\
\text { sensors }\end{array}$} & \multicolumn{2}{|c|}{ Equations } \\
\cline { 2 - 3 } $\mathrm{C}_{101}$ & $T=21^{\circ} \mathrm{C}$ & $T=62.5^{\circ} \mathrm{C}$ \\
& $\mathrm{M}_{101}=$ & $\mathrm{M}_{101}=$ \\
& $305.36 \mathrm{U}_{101}-0.5143$ & $305.45 \mathrm{U}_{101}-0.5094$ \\
\hline $\mathrm{C}_{102}$ & $\mathrm{M}_{102}=\mathrm{U}_{102}$ & $\mathrm{M}_{102}=$ \\
& & $0.9935 \mathrm{U}_{102}-0.5335$ \\
\hline $\mathrm{C}_{103}$ & $\mathrm{M}_{103}=$ & $\mathrm{M}_{103}=$ \\
& $1.0374 \mathrm{U}_{103}+0.0591$ & $1.1329 \mathrm{U}_{103}+0.1165$ \\
\hline
\end{tabular}

$\mathrm{U}_{\mathrm{j}}$ is the tension in $\mathrm{mV}$ given by the Personal Computer obtained by the sensor $\mathrm{i}$ and $\mathrm{M}_{\mathrm{i}}$ is the correspondence value of the mass in $\mathrm{kg}$.

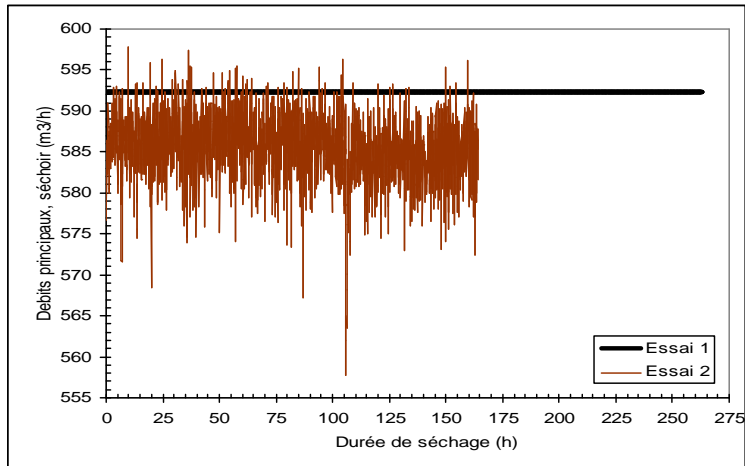

Figure 7a: Principal volumetric rate versus drying time (h) 


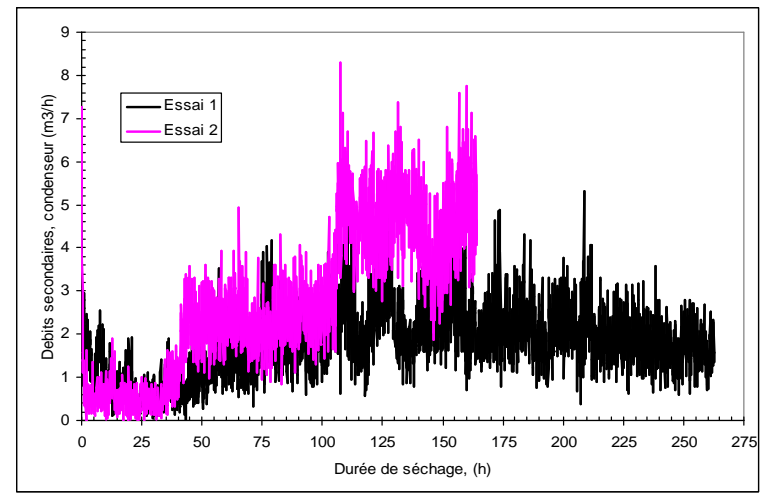

Figure 7b: Secondary volumetric rate versus drying time (h) Figure 7: Different volumetric rate

Table 3: Characteristics of the Planks Using During the Tests

\begin{tabular}{|c|c|c|c|c|c|}
\hline Species & $m_{f}(g)$ & $m_{0}(g)$ & $X_{f}(\%)$ & $M_{0}(g)$ & $X_{i}(\%)$ \\
\hline Ayous 1 & 23.25 & 22.002 & 5.67 & 628.85 & 27.4 \\
\hline Ayous 2 & 19.683 & 18.619 & 5.71 & 542.81 & 32.72 \\
\hline Species & $\begin{array}{c}\text { Anatomical } \\
\text { direction }\end{array}$ & Lxlxep $\left(\mathrm{dm}^{3}\right)$ & $M_{i}(g)$ & $M_{f}(g)$ \\
\hline Ayous 1 & quarter & $4.5 \times 1.2 \times 0.25$ & 801.1 & 664.5 \\
\hline Ayous 2 & False quarter & $4.5 \times 1.2 \times 0.25$ & 720.4 & 573.8 \\
\hline
\end{tabular}

$\mathrm{M}_{\mathrm{i}}$ : Initial mass (in the start of the drying) of the plank; $\mathbf{M}_{\mathrm{f}}$ : Final mass of the plank in the end of the drying process; $\mathrm{m}_{\mathrm{f}}$ : Mass of the small sample extract in the plan kat the end of the drying in order to determine the final water content and to estimate the initial water; $\mathrm{m}_{0}$ : Anhydrous mass of the small sample; $\mathrm{x}_{\mathrm{f}}$ : Water content of the plank (equal to the water content of the small sample) in the end of the drying; $\mathbf{M}_{0}$ : Anhydrous mass of the plank; $\mathrm{X}_{\mathrm{i}}$ : Initial water content (at the start of the drying) of the plank.

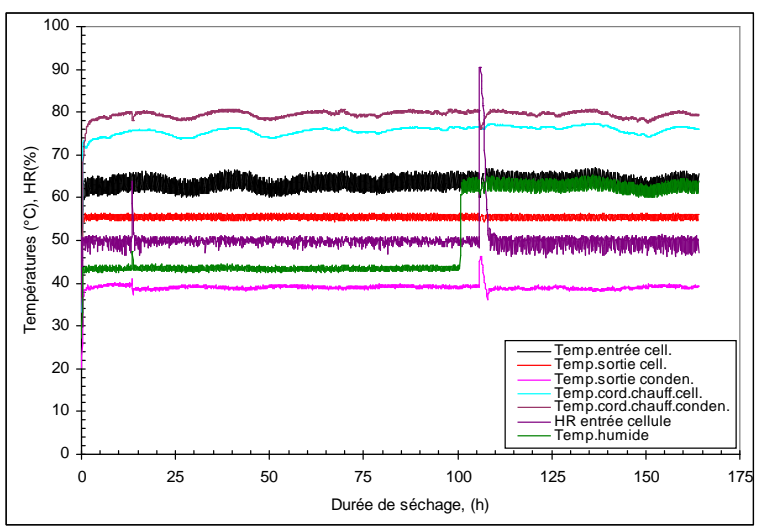

Figure 8: Evolutions of $T$ and $H R$ of the air versus drying time

Figure 8 above shows that humid temperature rejoined dry temperature, for this reason, the demineralized water in the box which contains the humid thermocouple is dried after $100 \mathrm{~h}$ of the drying. After this duration, it becomes difficult to estimate the others characteristics of the humid air.

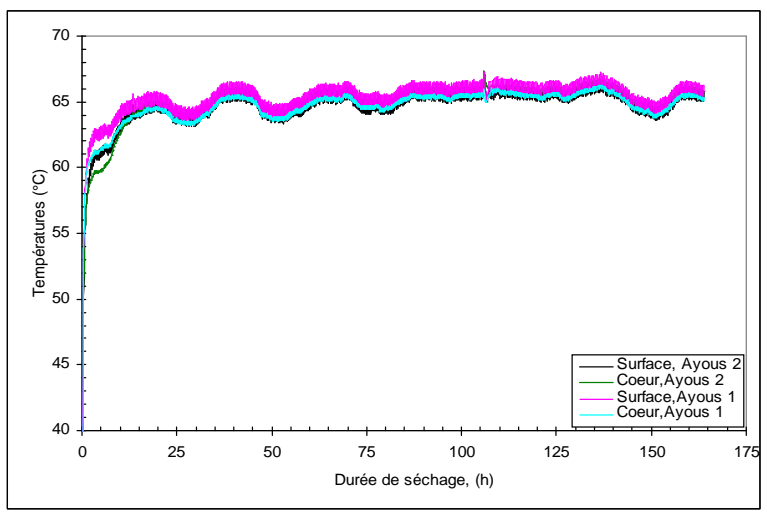

Figure 9: Evolutions of $T$ at heart and at surface versus drying

time

Figure 9 shows the evolution of the temperatures of the heart and the surface of ayous wood. We noticed that in the start of the drying, a clear distinction is observed. In the continuation, no distinction is observed because the gradient of the temperature becomes small.

\subsection{Drying kinetics}

Figure 10 shows the evolutions of water contents of ayous and fraké woods. We noticed that the water contents of ayous woods rejoined quickly in spite of the differences of their initial water contents. This shows that it is easy to observe the drying of a stack of ayous wood. The period where the temperature increases may be sufficient to bring nearer the water contents of the different components of the stack. In addition, we noticed that the water contents of the ayous and fraké woods are near rapidly. It is possible to dry these two species together. Figure 11 shows the evolutions of the water contents in the heart of the ayous plank. It is with satisfaction that we noticed a similar evolution yet the two planks coming from the different trees. This shows the easiness to dry the ayous planks coming from the different trees. In addition, the water contents in the heart are near of the average water content: then, water content is uniform in the thickness of the plank.

In order to have a clear idea of the drying kinetic of ours woods, we have used an enclosure most controlled where we have putted the samples which the characteristics and the anatomical directions are given in the table 4 below. The air rate near of ours samples is estimated to $0.25 \mathrm{~m} / \mathrm{s}$. The temperatures are given in the figure 12 below. Figure 13 gives the drying kinetic obtained. When the duration of the drying is inferior to $111 \mathrm{~h}$, we may constructed the graph $\ln \left(X_{\text {red }}\right)=f(t)$ in order to estimate the mass diffusion coefficient in the wood where $T_{h}$ is the humid temperature and $T_{s}$ is the dry temperature. Figure 14 presents a coherent theoretical and practical approach. We obtained a mass diffusion coefficient equal to $3.8 \times 10^{-10} \mathrm{~m}^{2} / \mathrm{s}$ coming from the first order of the Crank's equation of diffusion (4a) transformed below [5]. D is the mass diffusion coefficient, e the thickness of the sample, $t$ the drying time, $X_{e q}$ is the equilibrium water content, $X_{0}$ the initial water content and $X$ the water content during the drying process in each $t$.

$\ln \left(X_{\text {red }}\right)=\ln \left(\frac{X-X_{e q}}{X_{0}-X_{e q}}\right)=\ln \left(\frac{8}{\pi^{2}}\right)-\frac{\pi^{2} D}{e^{2}} t(4 a)$

We obtained:

$\operatorname{Ln}\left(\mathrm{X}_{\text {red }}\right)=-6 \times 10^{-6} \mathrm{t}-0.218$ 
The time space is good chosen because $\ln \left(\frac{8}{\pi^{2}}\right)=-0.21$. A good determination of the parameter $\mathrm{D}$ is necessary to simulate numerically the conventional and solar dryers $[6,7]$.

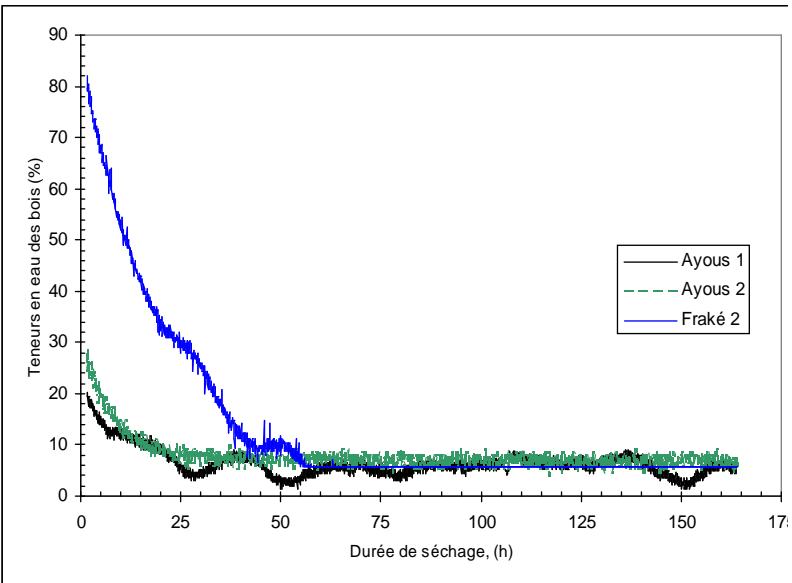

Figure 10: Average water contents of ours woods

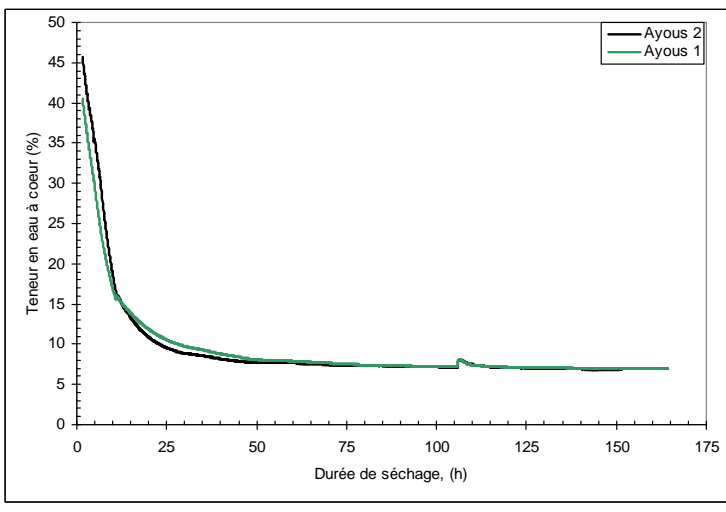

Figure 11: Water content at the heart of ours woods

Table 4: Characteristics of the Planks

\begin{tabular}{|c|c|c|c|}
\hline Species & $\begin{array}{c}\text { Dimensions } \\
(\text { Lxlxep })\left(\mathrm{cm}^{3}\right)\end{array}$ & $\begin{array}{c}\text { Annual } \\
\text { growth rings }\end{array}$ & $\begin{array}{c}\text { Anatomical } \\
\text { direction }\end{array}$ \\
\hline Ayous & $36.5 \times 11.7 \times 2.5$ & False flatsaw & Radial \\
\hline
\end{tabular}

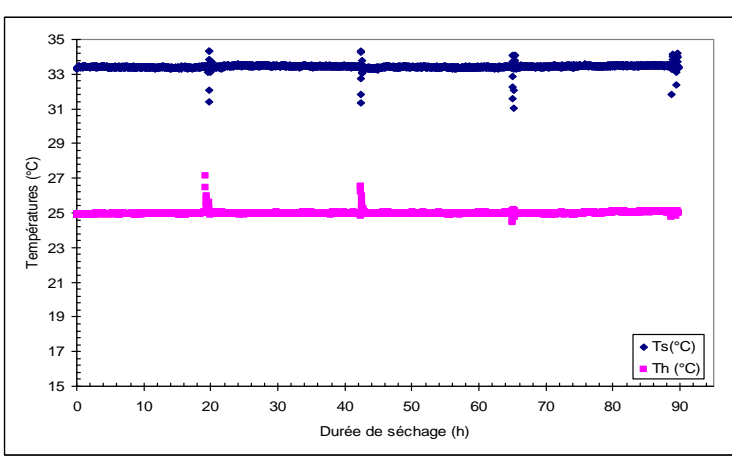

Figure 12: Evolutions of $T_{h}$ and $T_{s}$ versus drying time in a steady condition

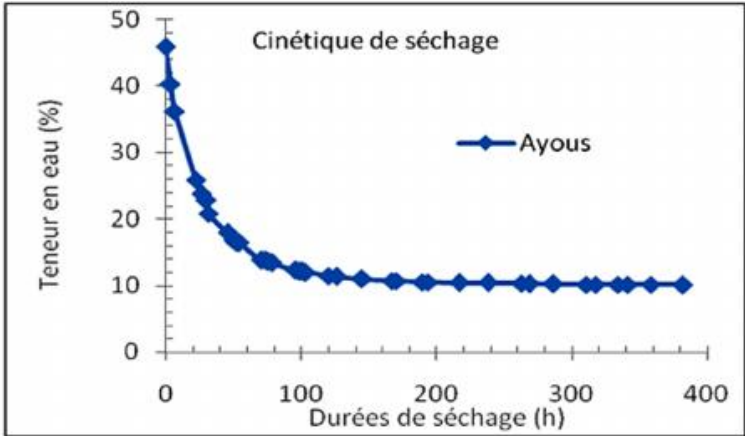

Figure 13: Drying kinetic in a very steady condition

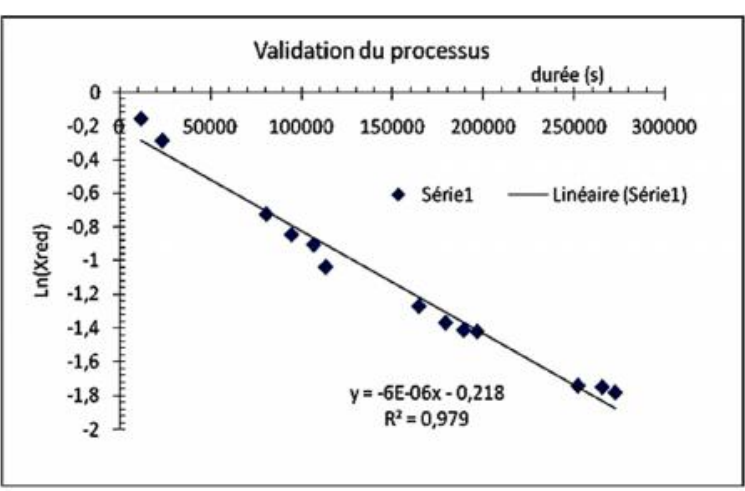

Figure 14: Variation of $\operatorname{Ln}(\mathrm{Xred})$ versus drying time for the deduction of mass diffusion coefficient

\subsection{Cost Price of the Wood Drying}

\subsubsection{Necessary energy to liberate bound water in the wood}

In ours previous works [5], we have modelling the isotherms of desorption of the ayous wood. These are given below:

$$
\begin{aligned}
& X_{e q}=\frac{b_{1} X_{m} H R}{\left(1-b_{2} H R\right)\left(1-b_{2} H R+b_{1} H R\right)}, \\
& b_{2}=2,2527 \exp \left(\frac{-2760,576}{R T}\right) \\
& X_{m}=-0,0009 T+0,3608 C=27,085 \exp \left(\frac{-2203,14}{R T}\right) \\
& b_{1}=C b_{2}
\end{aligned}
$$

With HR is relatively humidity of the air given in decimal, $\mathrm{T}$ is the dry temperature of the air given in $\mathrm{K}, \mathrm{R}$ is the constant of perfect gases $(\mathrm{R}=8.321 \mathrm{~J} /(\mathrm{mol} . \mathrm{K}))$ and $\mathrm{X}_{\text {eq }}$ is the equilibrium water content of the ayous wood obtained in decimal. In the study [5], we have determined the necessary energy to liberate a mole of water where we have used the Clausius-Clapeyron's formula relative at two isotherms $\mathrm{T}_{1}$ and $\mathrm{T}_{2}$.

$$
\Delta H_{b}=\frac{R}{\frac{1}{T_{2}}-\frac{1}{T_{1}}} \ln \left(\frac{H R_{2}}{H R_{1}}\right)
$$

With five experimental isotherms, we have determined many experimental points. The correlation of these points gives: 
$-\Delta H_{b}=7847,61 \exp \left(-12,38 X_{e q}\right)$

The correlation obtained on the resinous wood is [5]:

$-\Delta H_{b}=5040 \exp \left(-14 X_{e q}\right)$

We noted a difference between the two relations because the history and the type of the samples used to obtain the relation (7b) are unknown. To estimate the necessary energy to liberate all the moles of bound water at the fiber saturation point $\mathrm{H}_{\mathrm{s}}$ to final water content $\mathrm{I}_{\mathrm{f}}$, we used the relation [5] :

$Q_{1}=\int_{H_{s}}^{H_{f}} \Delta H_{b} d X_{e q}$

With $\mathrm{H}_{\mathrm{s}}=29.44 \%$ [5] and $\mathrm{H}_{\mathrm{f}}=9.34 \%$ [5].

We obtained $\mathrm{Q}_{1}=182.8916 \mathrm{cal} / \mathrm{mol}$. The quantity of bound water to extract in each stack gives:

$m_{e / \text { pile }}=\rho_{o} V_{b}\left(H_{s}-H_{f}\right)$

The volume of one plank $V_{b}$ in one stack established in the sawmill SEEF.SA of Douala-Cameroon with the porosity equal to 0.47 . The volume of one stack is $2.60 \mathrm{~m}^{3}$, we obtained $\mathrm{V}_{\mathrm{b}}=1,378 \mathrm{~m}^{3}$. We have the anhydrous density of the ayous wood $\rho_{o}=336 \mathrm{~kg} / \mathrm{m}^{3}$, thus we obtained $\mathrm{m}_{\mathrm{e} / \mathrm{pile}}=93.065 \mathrm{~kg}$. We can to estimate the total energy needed to extract all bound water in the thickness of the plank of the stack. We have obtained : $\mathrm{Q}_{\mathrm{T} 1}=3952.62 \mathrm{~kJ}$.

\subsubsection{Energy needed to evaporate the water liberated in the wood}

We can to estimate the mass of water to evaporate during the drying process. It is the sum of the quantities of liberated bound water and free water in the stack, calling in this study "eau liberée". We have:

$m_{\text {eau libérée }}=\rho_{o} V_{b}\left(X_{i}-H_{f}\right)$

Known that initial water content is $\mathrm{X}_{\mathrm{i}}=51 \%$, we obtained $\mathrm{m}_{\text {eaulibérée }}=192.89 \mathrm{~kg}$. Thus, the energy needed to evaporate the water liberated in the wood $\mathrm{Q}_{\text {eaulibéré }}$ is given by the relation:

$\mathrm{Q}_{\text {eaulibérée }}=\mathrm{m}_{\text {eaulibérée }} \mathrm{L}_{\text {veau }}=435929.44 \mathrm{~kJ}$

$\mathrm{L}_{\text {veau }}$ is the latent heat of the evaporation of water.

\subsubsection{Energy needed to increase the temperature of the wood}

The energy needed to increase mass water and solid mass of the wood from the ambient temperature of the Douala to the maximal temperature noted in the drying table of the studied wood. The Thermophysical properties of the wood are estimated at the average temperature between those the ambient and maximal. We noted $\mathrm{Q}_{\text {totale2 }}$ this energy and we have:

$Q_{\text {total } 2}=\rho_{h} V C_{P h}\left(T_{\text {sech }}-T_{\text {amb }}^{\prime}\right)=57019.2 \mathrm{~kJ}$

$\rho_{h}($ at $51 \%)=528.444 \mathrm{~kg} / \mathrm{m}^{3}$

$C_{p h}=1666 \mathrm{~J} /(\mathrm{kg} . \mathrm{K}), T_{\text {sech }}=353.15 \mathrm{~K}, T_{a m b}=306.15 \mathrm{~K}$

\subsubsection{Energy needed to move the air in the dryer}

It is necessary to estimate the energy needed to move the mass of the air in the dryer in order to homogenize the characteristic of the air in the dryer and to obtain a homogeneous drying. We have:

$W=\rho_{\text {air }} v_{\text {air }} g V t$

Known that the drying duration is 10 days and the rate of the air is $\mathrm{V}=1.5 \mathrm{~m} / \mathrm{s}$, the volume of the enclosure of the dryer is $\mathrm{v}_{\text {air }}=252 \mathrm{~m}^{3}$, thus we have $\mathrm{W}=1149.7 \mathrm{kWh}$. Also, known that 48 stacks are in the dryer [1], for one stack, it is needed $\mathrm{W} / 48=86227.5 \mathrm{~kJ}$.

\subsubsection{Energy needed to heat the walls of the dryer}

The walls of the dryers are doing by the materials which less consumed energy. Nearer $10 \%$ of the energy is needed to heat the walls.

\subsubsection{Cost price of the drying}

Thus, totale energy needed to dry one stack is $\mathrm{Q}_{\text {Totale }}=178.179 \mathrm{kWh}$. In addition, known that the liberated mass of water by stack is $m_{\text {eau libérée }}=192.89 \mathrm{~kg}$, we can to estimate the energy needed to liberate one $\mathrm{kg}$ of water. We obtained $0.924 \mathrm{kWh} / \mathrm{kg}$. This result is satisfactory because the literature announces it between $0.6 \mathrm{kWh} / \mathrm{kg}$ and $2.5 \mathrm{kWh} / \mathrm{kg}$ [8]. This ratio becomes important when the wood to dry is most hard and delicate.

The Cameroonian's price of the kWh of energy was estimated to 100FCFA. Thus, the sum to buy this energy by stack is 17818FCFA, approximately 27euros (€). Known that the average price of the drying of wood is $50000 \mathrm{FCFA} / \mathrm{m}^{3}$ $\left(76.22 € / \mathrm{m}^{3}\right)$, value which can to be modified in function of the type of wood, the 48 stacks for to fill up the dryer (SEEF.SA) give a benefit (without tax and the price of the light and others) estimated to $2451936 \mathrm{FCFA}$ ( $3718 €$ approximately) all the 10 days of the drying. The problem is to make change mentality of the joiners. These joiners must understand that when the planks are dried, the tools in wood are stability in the time, so are in the good quality. The maintenance of the forest is also optimized. This second part shows that the optimal maintenance of the forest can to give most money and it is created many jobs.

Some driers use indirect dryers where the combustion of the wood waste is using to increase the temperature of the coolant fluid. In this study, known that the lower heating value of the tropical wood is estimated to $5.169 \mathrm{kWh} / \mathrm{kg}$ [9], a quantity to $34.48 \mathrm{~kg}$ of the ayous wood is needed to give the $178.179 \mathrm{kWh}$ of energy to dry one stack, approximately the $7.45 \%$ of the mass of one stack. It is a minimal value because we do not take in consideration many losses such as the energy exchanged by conduction, by convection and by radiation between the heated air and the others components of the dryer. In addition, the biomass used is often the wood waste made of many types of wood which change the value of the lower heating value, thus the needed mass for the combustion. We noted that the smokes are flowed in the nature in the proportion of $20.2 \%$ of the $\mathrm{CO}_{2}$. 


\section{Conclusions}

This study on the drying of ayous wood and the maintenance of the dryer shows that:

- The calibration of apparatus of the measure of dryer is important to control the drying of wood;

- The electric properties of wood can to be use to predict the water content and temperature during the drying;

- Mass diffusion coefficient extracts of the $1^{\text {st }}$ order of the Crank's result shouldn't use to simulate the drying of wood in all the duration of the drying;

- The drying of wood is an economic activity which gives most money and permits to optimize the maintenance of the forest. During this test, $26.5 \%$ of the mass of stack is reduced, percentage which represents the evacuated water from the stack. Initial water content of the stack is $51 \%$. The percentage of the extract water can to be important if the initial water content increases;

- In the perspective to use the combustion of wood waste in order to increase the temperature of the cooler fluid, a minimum of the mass of ayous wood waste is $7.45 \%$ of the mass of the wood to dry can to be burnt, value obtained with neglected some losses of heat.

\section{Acknowledgments}

This work is a part of a Post Doctorate research funded by the International Tropical Timber Organization (ITTO).Principal author wishes to acknowledge this International Organization. Additionally, he gratefully acknowledges Mr. Tristan STEIN, the Technician of LERMaB, University of Lorraine-France, for the sampling collection of ours woods and the setting of apparatus measures. Also, I wish that Mr. Pierre HAGUE of the sawmill SEEF.SA situated at Douala-Cameroon receives my great thanks for providing the wood species required for this research.

\section{References}

[1] Simo-Tagne M. Contribution à l'étude du séchage des bois tropicaux au Cameroun: Aspects caractérisation, modélisation multi échelle et simulation. Le cas des bois d'ayous et d'ébène, Ph.D Thesis of the University of Yaoundé I, Cameroon, 2011.

[2] Okelle S. O. Cameroon Tribune, Thursday 8th January $2009 \mathrm{~N}^{\circ} 9262 / 5451,2009$.

[3] Rémond R. Approche déterministe du séchage des avivés de résineux de fortes épaisseurs pour proposer des conduites industrielles adaptées, Ph.D Thesis of the ENGREF, France, 2004.

[4] Kouchade A.C. Détermination en routine de la diffusivité massique dans le bois par la méthode inverse à partir de la mesure électrique en régime transitoire, Doctorate Thesis of the ENGREF, France, 2004.

[5] M. Simo-Tagne, A. Zoulalian, D. Njomo, B. Bonoma. Modelisation of desorption isotherms and estimation of the thermophysical and thermodynamic properties of tropical woods in Cameroon: the case of Ayous and ebony woods, Revue des Energies Renouvelables, Vol.14, ํ3, 487-500, 2011.

[6] M. Simo-Tagne. Numerical study of heat and mass transfer during the thermal drying of tropical woods. Int. J. Thermal \& Environmental Engineering 2014; 8 :9-15, DOI: $10.5383 /$ ijtee.08.01.002

[7] M. Simo-Tagne. Laboratory simulation of solar dryer for tropical woods: the case of ebony (diospyros crassiflora) Int. J. Thermal \& Environmental Engineering 2015; 9 :1-6, DOI: $10.5383 /$ ijtee.09.01.001

[8] P.Girard, F.Pinta, L.V.D.Steene. Valorisation énergétique des sous produits des scieries, Bois et forêts des tropiques, $\mathrm{n}^{\circ} 277,5-17,2003$.

[9] J. Doat. Le pouvoir calorifique des bois tropicaux, Bois et Forêts des Tropiques, $\mathrm{N}^{\circ} 172,33-47,1977$. 